\title{
Heißt klein anders?
}

\section{Liebe Leserinnen und Leser,}

wer sich in den vielen Lehrbüchern der Betriebswirtschaftslehre umschaut, kann durchaus den Eindruck gewinnen, sie seien für Großunternehmen geschrieben. Das hat viele Gründe. Es beginnt bei den Autoren. Wenn Professoren Kontakte in die Praxis haben, sind dies bevorzugt große Unternehmen. Hier findet man die Ansprechpartner, mit denen man über neue Entwicklungen und Instrumente diskutieren kann. Hier sind genügend Ressourcen vorhanden, um Innovationen umzusetzen. Hier finden sich Probleme in einer Komplexität, die Professoren herausfordert. Hier findet man die Spezialisierung vor, die für die eigene Forschung neue Ideen liefert - und hiermit sind längst nicht alle Aspekte angesprochen.

Kleine und mittelständische Unternehmen fühlen (auch deshalb) häufig eine deutliche Distanz zum akademischen Bereich. Sie scheinen andere Probleme mit anderen Mitteln lösen zu müssen. Was bei großen Unternehmen formal abzulaufen hat, funktioniert bei kleinen informell. Direkte persönliche Führung ersetzt aufwendige Führungsinstrumente. Viele sinnvolle Instrumente scheitern an begrenzten finanziellen und personellen Ressourcen. Heißt das, dass es eine spezielle Betriebswirtschaftslehre für kleine und mittlere Unternehmen geben muss, dass dort ein „GroßunternehmensControlling" nicht passt?

Wir meinen nein! Die Unterschiedlichkeit in der konkreten Problemlösung darf nicht darüber hinwegtäuschen, dass das dahinterliegende Problem zumeist sehr ähnlich ist. Auch in mittelständischen Unternehmen gibt es zum Beispiel genügend Probleme und Ressourcen, eine Kostenrechnung zu betreiben, selbst wenn diese nicht so sophistiziert ausfällt wie in Großunternehmen. Auch in kleinen Betrieben macht es sehr viel Sinn, sich über die Kosten des Eigenkapitals Gedanken zu machen, selbst wenn an komplexe wertorientierte Steuerungsmodelle nicht im Mindesten zu denken ist.

Wir empfehlen folgende Heuristik: Gehen Sie davon aus, dass das Lehrbuchwissen grundsätzlich auch für kleine und mittlere Unternehmen gilt, selbst wenn die konkreten Lösungen an die Unternehmensgröße angepasst werden müssen.

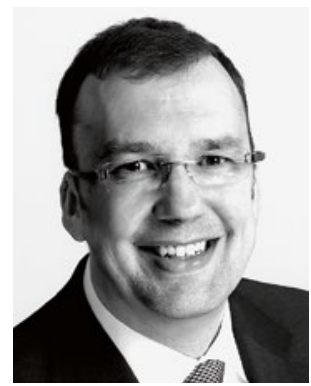

Utz Schäffer

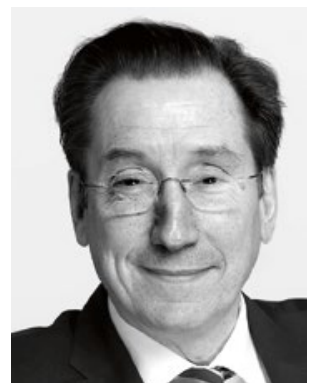

Jürgen Weber

Nicht nur unsere eigene Erfahrung „vor Ort“, sondern auch die umfangreichen Daten unseres WHU Controller Panels haben uns zu dieser Heuristik geführt. Die Daten zeigen nur wenige grundlegende Unterschiede in den Antworten aus kleinen und großen Unternehmen - schauen Sie doch unter www.whu-on-controlling.com selbst einmal nach! Natürlich hat ein großes Unternehmen deutlich mehr Controller als ein kleines; bezogen auf die Mitarbeiterzahl wird der Unterschied aber schon sehr gering. In den wichtigen „weichen“ Themen, wie den wahrgenommenen Rollen, dem Standing im Unternehmen, der internen Kundenorientierung und so weiter, antworten Controller aus kleinen wie aus großen Unternehmen praktisch gleich. Auch ein Controller aus einem kleinen Unternehmen kann deshalb von den Inhalten unserer Controlling \& Management Review profitieren - und dies nicht nur in einem entsprechenden Schwerpunktheft!

Viel Vergnügen bei der Lektüre wünschen Ihnen
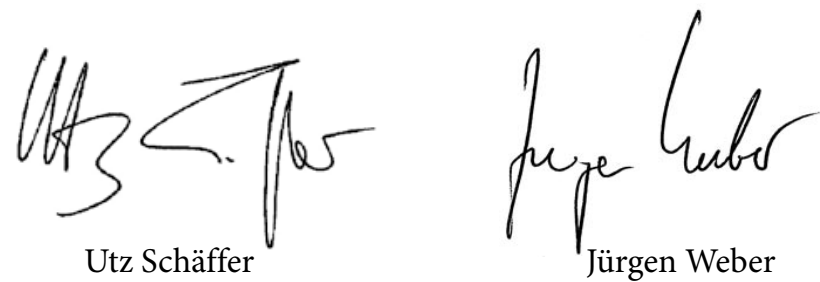